\title{
Impact of Airspace Charges on Transatlantic Aircraft Trajectories
}

\author{
Banavar Sridhar ${ }^{1}$ \\ NASA Ames Research Center, Moffett Field, CA 94035-1000 \\ Hok K. $\mathrm{Ng}^{2}$ \\ University of California, Santa Cruz, Moffett Field, CA 94035-1000 \\ Florian Linke ${ }^{3}$ \\ DLR Air Transportation Systems, Hamburg, Germany \\ Neil Y. Chen ${ }^{4}$ \\ NASA Ames Research Center, Moffett Field, CA 94035-1000
}

\begin{abstract}
Aircraft flying over the airspace of different countries are subject to over-flight charges. These charges vary from country to country. Airspace charges, while necessary to support the communication, navigation and surveillance services, may lead to aircraft flying routes longer than wind-optimal routes and produce additional $\mathrm{CO}_{2}$ and other gaseous emissions. This paper develops an optimal route between city pairs by modifying the cost function to include an airspace cost whenever an aircraft flies through a controlled airspace without landing or departing from that airspace. It is assumed that the aircraft will fly the trajectory at a constant cruise altitude and constant speed. The computationally efficient optimal trajectory is derived by solving a non-linear optimal control problem. The operational strategies investigated in this study for minimizing aircraft fuel burn and emissions include flying fuel-optimal routes and flying cost-optimal routes that may completely or partially reduce airspace charges en route. The results in this paper use traffic data for transatlantic flights during July 2012. The mean daily savings in over-flight charges, fuel cost and total operation cost during the period are $17.6 \%, 1.6 \%$, and $2.4 \%$ respectively, along the costoptimal trajectories. The transatlantic flights can potentially save $\$ 600,000$ in fuel cost plus $\$ 360,000$ in over-flight charges daily by flying the cost-optimal trajectories. In addition, the aircraft emissions can be potentially reduced by 2,070 metric tons each day. The airport pairs and airspace regions that have the highest potential impacts due to airspace charges are identified for possible reduction of fuel burn and aircraft emissions for the transatlantic flights. The results in the paper show that the impact of the variation in fuel price on the optimal routes is to reduce the difference between wind-optimal and cost-optimal routes as the fuel price increases. The additional fuel consumption is quantified using the $30 \%$ variation in fuel prices during March 2014 to March 2015.
\end{abstract}

\section{Introduction}

A irlines plan aircraft trajectories that minimize the cost of operations between city pairs. Currently, aircraft cruise along a horizontal route following a predetermined altitude and speed profile. The selection of the horizontal route, altitude and speed profiles is made to accommodate several factors like terminal area constraints, restricted airspace and weather disturbances. The resulting aircraft trajectory consumes more fuel and produces more emissions than optimal four-dimensional trajectories. Aircraft flying through the airspace of different countries are subject to over-flight or en route charges as part of the air navigation services fees. These charges vary from country to country. In general, over-flight charges are not collected if either the origin or the destination city-pair is within the respective country. On the contrary, some countries (e.g. in Europe) collect en route charges instead that also

\footnotetext{
${ }^{1}$ Senior Scientist for Air Transportation Systems, Aviation Systems Division, Fellow.

${ }^{2}$ Research Scientist, U.C. Santa Cruz, MS 210-8, Member AIAA.

${ }^{3}$ Team Leader for Air Traffic Infrastructures and Processes.

${ }^{4}$ Aerospace Research Engineer, Systems Modeling and Optimization Branch, MS 210-10, Member AIAA.
}

1

American Institute of Aeronautics and Astronautics 
apply to departing and landing aircraft. These airspace charges could be a flat fee or directly proportional to the over-flight distance and may be modified depending on the aircraft weight. The effect of airspace charges is to make the aircraft trajectory deviate from the wind-optimal trajectory and result in a trajectory that consumes more fuel. Thus, airspace charges result in more emissions in addition to the extra cost incurred by airlines. The airspace costs have a significant impact on long international routes. The airspace costs cover the cost of providing services to over-flights. There is a trade-off between generating revenue for supporting services and the resulting extra emissions of $\mathrm{CO}_{2}$ and other gases.

Past studies have described the strategies for reducing airlines operating cost by utilizing the flight management computer during cruise flight $^{1-2}$. Several studies have described the inefficiencies of the current routing structure and potential benefits resulting from flying optimal routes $^{3-8}$. There is extensive literature on developing optimal trajectories for an aircraft that minimizes a cost function while satisfying constraints ${ }^{9}$. The aircraft models vary in complexity and the optimization is done based on different objective cost functions with or without wind. Most of the cost functions used in the analysis are minimum fuel and minimum time; the effect of airspace charges on the development of optimal trajectory has not been fully realized.

This paper develops an optimal route between city pairs by modifying the cost function to include an airspace cost whenever an aircraft flies through a controlled airspace without landing or departing from that airspace. It is assumed that the aircraft will fly the trajectory at a constant cruise altitude and constant speed. The computationally efficient optimal trajectory is derived by solving a non-linear optimal control problem ${ }^{9}$.

Section II describes the different types of airspace charges and models them suitably for inclusion in an optimization procedure. Section III explains the optimal trajectory generation for cruising aircraft. Section IV describes the application of the trajectory optimization algorithm for calculating wind-optimal and wind-optimal routes constrained by airspace costs. The routes examined are transatlantic routes across the busiest oceanic airspace in the world, which carried approximately 460,000 flights during 2012. Section V describes the impact of airspace charges on additional fuel and $\mathrm{CO}_{2}$ emissions and how the results are affected by the recent fluctuations in fuel prices. Conclusions and future work are described in Section VI.

\section{Airspace Charge Models}

The Air Navigation Service Provider (ANSP) charges aircraft travelling in controlled airspace for the use of airspace services. The charges vary from country to country and may depend on the airport and type of aircraft. Some of the common types of charges are (a) en route or over-flight charges, (b) terminal charges and (c) communication charges.

The en route charges can be generally expressed for a country i as $\mathrm{C}_{e i}$,

$$
C_{e i}=U_{e i} f_{e i}(M T O W) d_{i}
$$

where $\mathrm{U}_{\mathrm{ei}}$ is the charge per unit distance, $f_{\mathrm{ei}}$ is a function of MTOW, the maximum take-off weight of the aircraft expressed in metric tons $(1000 \mathrm{~kg})$ and $\mathrm{d}_{\mathrm{i}}$ is the distance travelled in the country $\mathrm{i}$. Some commonly used functions $f_{\text {ei }}$ are $(\mathrm{MTOW} / \mathrm{a})^{\mathrm{b}}$, where a takes values like $(1,50,100, .$.$) and \mathrm{b}$ takes values like $(0,1,0.5,0.7, \ldots)$. The FAA charges 35 cents $/ \mathrm{km}$ over the continental US and 13 cents $/ \mathrm{km}$ in the oceanic airspace. Table 1 shows the en-route charges for some of the countries in the world ${ }^{10-11}$. For better comparability the example column lists the charges levied on a Boeing 747-400 with a MTOW of 448 metric tons per km through the corresponding airspace.

The terminal charges, $\mathrm{C}_{\mathrm{t}}$, are levied on departing and landing flights and can be expressed as

$$
C_{t i}=U_{t i} f_{t i}(M T O W)
$$

where $\mathrm{U}_{\mathrm{ti}}$ is the unit terminal rate and $f_{\mathrm{ti}}$ is a function of MTOW in the country i. Some commonly used functions $f_{\mathrm{ti}}$ are $(\mathrm{MTOW} / \mathrm{a})^{\mathrm{b}}$, where a takes values like $(1,50,100, .$.$) and \mathrm{b}$ takes values like $(0,1,0.5,0.7, \ldots)$. The terminal charges depend on the airport. Table 2 provides examples of terminal charges for some selected airports in different countries. The column on the right lists the landing and departure charges for a Boeing 747-400 with a MTOW of 448 metric tons for different airports for comparison. It should be noted that terminal charges do not have an impact on the wind-optimal trajectories between city pairs.

In addition to en route and terminal charges, airlines are charged for International Communication Services (ICS). The ICS charge covers the cost of air-ground radio frequencies and certain other communication links 
provided or made available to an aircraft during the course of an international flight. As an example, the ICS charge for position reporting using voice and data link in the Gander Oceanic FIR is \$22.04 and \$93.24 respectively.

Table 1. Airspace Charges

\begin{tabular}{|l|c|c|c|l|c|}
\hline \multicolumn{1}{|c|}{ Country } & $\mathrm{U}_{\mathrm{ei}}(\$ / \mathrm{km})$ & $\mathrm{a}$ & $\mathrm{b}$ & Remarks & Example $(\$ / \mathrm{km})$ \\
\hline United States & 0.36 & 1 & 0 & & 0.36 \\
\hline United States (Oceanic) & 0.14 & 1 & 0 & & 0.14 \\
\hline Canada & 0.03 & 1 & 0.5 & & 0.73 \\
\hline Canada (Gander Oceanic) & 93.24 & & & Flat rate in Canadian\$ & \\
\hline Portugal (Santa Maria) & 0.14 & 50 & 0.5 & & 0.41 \\
\hline Ireland & 0.39 & 50 & 0.5 & & 1.18 \\
\hline Ireland (Shanwick Oceanic) & 57.65 & & & Flat rate in US\$ (communication) & \\
\hline Germany & 0.99 & 50 & 0.5 & & 2.97 \\
\hline France & 0.84 & 50 & 0.5 & & 2.53 \\
\hline Denmark & 0.92 & 50 & 0.5 & & 2.74 \\
\hline Spain (continental) & 0.92 & 50 & 0.5 & & 2.75 \\
\hline Spain (Canaries) & 0.75 & 50 & 0.5 & & 2.24 \\
\hline
\end{tabular}

Table 2. Terminal Charges

\begin{tabular}{|l|l|c|c|c|c|}
\hline \multicolumn{1}{|c|}{ Country (Airport) } & $\mathrm{U}_{\mathrm{ti}}(\$)$ & $\mathrm{a}$ & $\mathrm{b}$ & Remarks & Example (\$) \\
\hline United States (San Francisco) & 4.57 & 0.454 & 1 & Landing Fee & $4,509.60$ \\
\hline United States (New York) & 6.00 & 0.454 & 1 & Landing Fee & $5,920.70$ \\
\hline U.K (London Heathrow) & 8.93 & 1 & 1 & Landing Fee & $4,000.00$ \\
\hline Netherlands (Amsterdam) & 11.38 & 1 & 1 & Landing Fee & $5,100.00$ \\
\hline Canada & 23.90 & 1 & 0.8 & Departure Fee & $3,158.06$ \\
\hline Germany (Frankfurt) & 235.56 & 50 & 0.7 & Departure Fee & $1,093.23$ \\
\hline France (Paris) & 298.79 & 50 & 0.7 & Departure Fee & $1,386.70$ \\
\hline Denmark (Copenhagen) & 224.54 & 50 & 0.7 & Departure Fee & $1,042.10$ \\
\hline Spain (Madrid) & 21.93 & 50 & 0.9 & Departure Fee & 157.80 \\
\hline
\end{tabular}

\section{Optimal Trajectory on Horizontal Plane}

This study integrates the technique of aircraft wind-optimal heading and the concept of Dynamic Programming (DP) to generate the optimal trajectories that minimize aircraft operating costs. The optimal aircraft turning locations are optimized based on the operation cost-to-go associated with each extremal generated by forward or backward integrations using the dynamical equations for optimal heading and aircraft motion from various points in the airspace. This section develops the optimal trajectory algorithm for cruising aircraft with en route airspace costs. Section III.A defines the cost functions for the minimizations of fuel cost and en route airspace charges. An efficient look-up system is developed in Section III.B for fast retrieval of associated airspace charges given aircraft locations and parameters. Section III.C summarizes the procedures for developing the optimal trajectories.

\section{A. Operating Cost Function}

This study develops a trajectory optimization algorithm that minimizes the total aircraft operating cost of a flight. The operating cost function depends on aircraft travel time, fuel price, aircraft fuel burn rate, and airspace charges incurred by the aircraft flying through different regions and countries. In this paper, the term "total aircraft operating cost" is used for the sum of these cost fractions. It does not include all the factors used in airline direct operating costs. The cost function is defined as:

$$
J=\int_{t_{0}}^{t_{f}}\left[C_{t}+C_{f} f(m, h)\right] d t+\sum_{i} U_{e i} f_{e i}(M T O W) d_{i}
$$

where $C_{t}$ is the cost coefficient of travel time, $C_{f}$ is the cost coefficient of fuel burn, $f(m, h)$ is the aircraft fuel burn rate that depends on the aircraft mass, $m$, and cruise altitude, $h$. The second term in Eq. (3) is the total over-flight charges as defined in Eq. (1) incurred along the aircraft trajectory. During cruise, the wind-optimal trajectory that is 
time and fuel optimal can be obtained by neglecting the airspace charges in the cost function to include only aircraft fuel consumption in the optimization. The fuel-only cost is defined as:

$$
J=\int_{t_{0}}^{t_{f}} C_{f} f(m, h) d t
$$

The optimization algorithm discussed in the next subsection remains unchanged when either cost function is used.

\section{B. Over-flight Charge System}

A system is designed for fast identification of the airspace charges incurred by aircraft flying through different regions and countries. The over-flight charges need to be computed along all potential trajectories. They are calculated together with aircraft fuel cost providing the total operation cost for trajectory optimization. In general, en-route aircraft can be charged by flown distance or a flat fee depending on the invoked airspace. The system keeps a record of both types of airspace charges invoked by all possible optimal trajectories.

Figure 1 shows the over-flight charges for United States, Canada, Europe, and the oceanic airspace in the North Atlantic region. The charges vary from country to country. They are also different over continental and oceanic regions. The colored polygons depict the airspaces that charge en route aircraft by the flown distance. The dollars charged per kilometer of flown distance are shown by the color bar for an aircraft with a MTOW of 450 metric tons. In general, United States and Canada have a relatively lower rate than that of European countries. The airspaces that have constant charges for en route aircraft are depicted by the polygons with dashed line. The corresponding charges are also provided.

\section{Aircraft Trajectory Design}

The equations of motion for an aircraft traveling with true air speed $V$ at a constant altitude $h$ above the spherical Earth's surface and the dynamical equation for the wind-optimal heading are:

$$
\dot{\phi}=\frac{V \cos \psi+u(\phi, \theta, h)}{R \cos \theta}, \dot{\theta}=\frac{V \sin \psi+v(\phi, \theta, h)}{R}, \dot{\psi}=\frac{-F_{\text {wind }}(\psi, \phi, \theta, u, v, V)}{R \cos \theta},
$$

subject to the assumptions that thrust equals drag, flight path angle is zero, and the boundary constraints are met. $\phi$ is longitude and $\theta$ is latitude, $\psi$ is heading angle, and $R$ is the Earth's radius. $F_{\text {wind }}(\psi, \phi, \theta, u, v, V)$ is aircraft heading dynamics in response to winds and is expressed as:

$$
\begin{aligned}
& F_{\text {wind }}(\psi, \phi, \theta, u, v, V) \\
& =\left[-\sin \psi \cos \psi \frac{\partial u(\phi, \theta, h)}{\partial \phi}+\cos ^{2} \psi \sin \theta u(\phi, \theta, h)+\cos ^{2} \psi \cos \theta \frac{\partial u(\phi, \theta, h)}{\partial \theta}-\frac{\partial v(\phi, \theta, h)}{\partial \phi}\right. \\
& \left.\quad+\sin \psi \cos \psi \sin \theta v(\phi, \theta, h)+\cos \psi \sin \psi \cos \theta \frac{\partial v(\phi, \theta, h)}{\partial \theta}+V \cos \psi \sin \theta+\cos ^{2} \psi \frac{\partial v(\phi, \theta, h)}{\partial \phi}\right] .
\end{aligned}
$$

In equation (6), the east-component of the wind velocity is represented by $u(\phi, \theta, h)$, and the north-component of the wind velocity is represented $v(\phi, \theta, h)$. It is assumed that the Earth is a sphere and $R>>h$. The optimal aircraft heading in Eq. (6) is the result ${ }^{12}$ of applying Pontryagin's Minimum Principle ${ }^{9}$ to determine the heading angle that is assumed to be the control available for aircraft during cruise for minimizing the cost of travel time. In the case that an aircraft cruises at a single altitude, the minimum-time trajectory is completely specified by integrating Eqs. (5-6) simultaneously from the origin to the destination using the optimal initial aircraft heading. Note that the minimumtime trajectory is fuel-optimal for aircraft cruise at a constant altitude.

This study integrates the technique of aircraft wind-optimal heading and the concept of Dynamic Programming (DP) to generate the optimal trajectories that minimize aircraft operating cost. The optimal aircraft turning locations are optimized based on the operation cost-to-go associated with each extremal generated by forward or backward integrations using the dynamical equations for optimal heading and aircraft motion from various points in the airspace. The values of cost-to-go at various points in the airspace are computed using Eq. (3) or Eq. (4) along each extremal depending on the objective. The airspace charge system developed in Section IIB is applied to calculate 
potential over-flight charges with the aircraft fuel burn model for the calculation of cost-to-go when Eq. (4) is adopted for minimization of total operating cost.

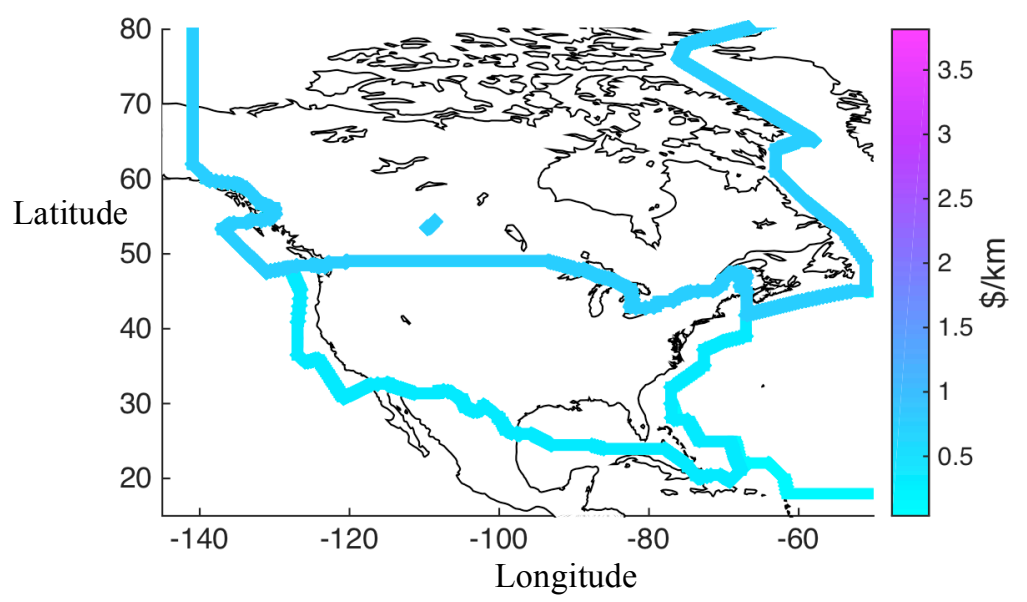

Figure 1(a)

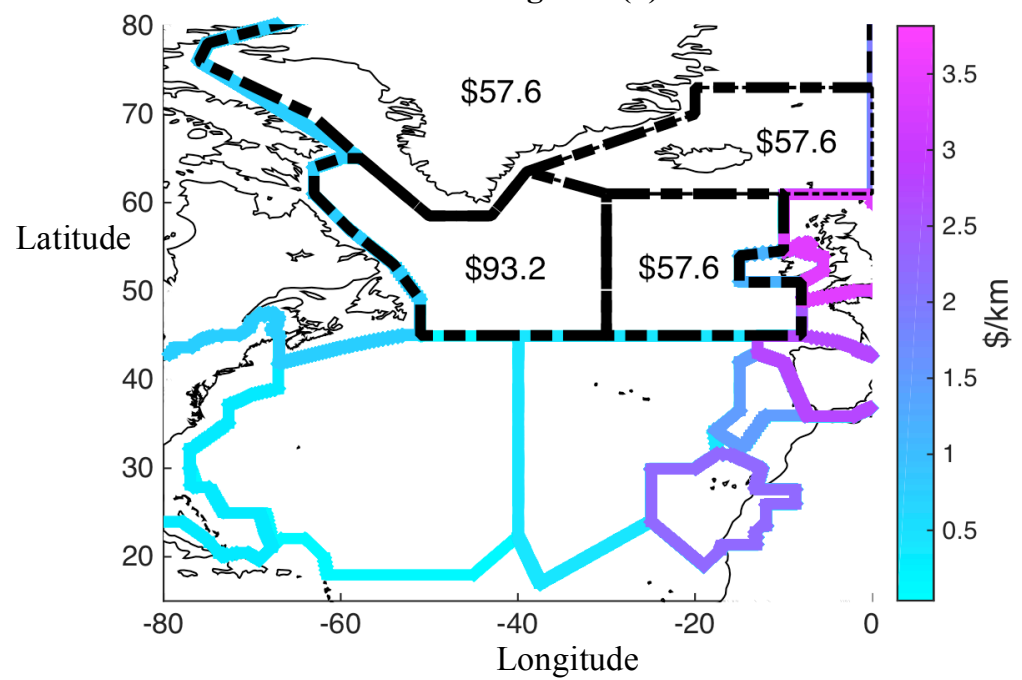

Figure 1(b)

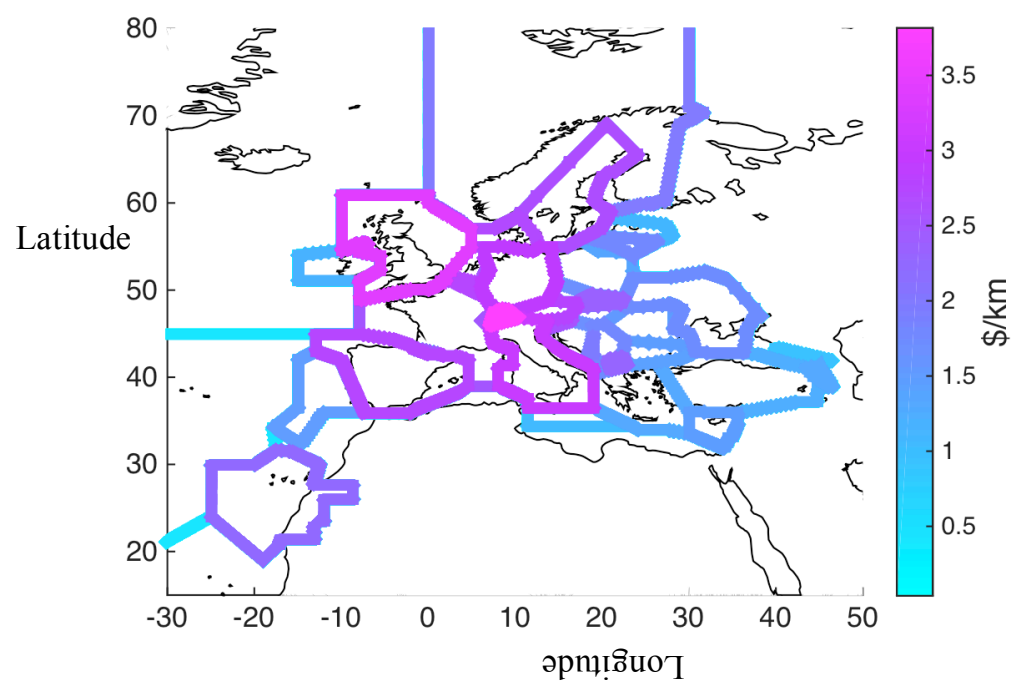

Figure 1(c)

Figure 1. Over-flight Charges for (a) United States and Canada, (b) North Atlantic Oceanic regions, and (c) Europe. 
Assuming that there are $\mathrm{N}-1$ possible turns and that each includes an adjustment in the aircraft heading with or without altitude change and $\mathrm{n}$ possible locations for each turn, a forward dynamic programming approach with $\mathrm{N}-1$ stages and $\mathrm{n}$ possible states in the set of $S_{N}$ for each stage can be formulated. The link cost is specified by Eq. (3) or Eq. (4) along the potential wind-optimal flight path. It is approximated by solving N-1 individual DP problems that each has one turn $(\mathrm{N}=2)$ in order to reduce the computational effort. The solution for each problem is the optimal aircraft turning location that becomes the origin for the subsequent problems. This algorithm, when applied in the real time, also accommodates the frequently updated weather forecast and dynamic nature of atmospheric conditions by optimizing the aircraft trajectory segments at each turning location using the most updated weather forecast. In this study $\mathrm{N}$ is limited so that turns occur only every 60 minutes.

\section{Trajectories for Transatlantic Flights}

This section presents results based on applying the optimal trajectory algorithm to calculate an aircraft trajectory in the presence of winds that minimizes the selected operational cost. Two operational costs are adopted in this study for trajectory optimization. These are the fuel-optimal cost and the total cost of fuel burn and airspace charges. Two groups of optimal trajectories are generated according to these two operational costs. They are compared to the actual fight tracks in terms of the fuel and over-flight costs to assess the potential benefits resulting from flying fueloptimal trajectories and evaluate the possible impact of over-flight charges on route structure, additional fuel burn and aircraft emissions. The trajectory computations are done using transatlantic air traffic and atmospheric data for July 2012.

The flight schedules and aircraft data are provided by the FAA's Traffic Flow Management System (TFMS). The cost-optimal trajectories are optimized based on Eq. (3) and the fuel-optimal trajectories are obtained similarly using Eq. (4). In this study, the computation of optimal trajectories adjusts wind-optimal headings every 60 minutes until the destination is reached. The optimal aircraft turning locations and the trajectory segments are solved as shown in Section III. In this paper, Eurocontrol's Base of Aircraft Data Revision 3.6 (BADA) ${ }^{13}$ provides the fuel consumption model. The emission model is based on the FAA's Aviation Environmental Design Tool (AEDT) ${ }^{14}$.

Section IV.A assesses flight trajectories along the fuel-optimal route, cost-optimal route and the recorded flight track for a transatlantic flight from Chicago, IL to London, England. Section IV.B presents the potential fuel benefits and savings of over-flight charges resulting from fuel-optimal trajectories and cost-optimal trajectories for the transatlantic flights during July 2012.

\section{A. Trajectories from Chicago to London}

Flight trajectories are generated for a transatlantic flight from Chicago (KORD) to London (EGLL) based on the fuel-optimal route, cost-optimal route and lateral flight track from TFMS. The fuel-optimal and cost-optimal trajectories are calculated at a constant cruise altitude same as that of actual flight track. The flight trajectories during initial takeoff, cruise and landing are simulated using the typical aircraft profiles for a Boeing 777-200 with heavy takeoff weight from BADA. They are analyzed to understand the variation of the horizontal route structure due to the en route airspace charges. The three trajectories are compared in terms of fuel burn, $\mathrm{CO}_{2}$ emissions and over-flight charges. The terminal charges and the ICS communication charges are assumed to be the same for these trajectories and not considered in this example. Figure 2 shows the horizontal fuel-optimal and cost-optimal trajectories, and recorded flight track in magenta, cyan, and blue, respectively for an eastbound flight from Chicago to London departing around 23:00 EDT on August 18, 2014.

The fuel-optimal trajectory is located at higher latitudes than that of the flight track. The travel time along the fuel-optimal trajectory is 418 minutes and the fuel burn is $55,100 \mathrm{~kg}$. The fuel-optimal trajectory flies over three Canadian Centers for a total of 2,131 km. It traveled 2,904 km through GANDER, SONDRESTROM, and SHANWICK oceanic FIRs; and it also crosses Shannon (EISN) FIR for $348 \mathrm{~km}$. The over-flight charges are $\$ 1,800$ for a flight with a MTOW of 287 metric tons based on Eq. (1) and Table 1.

The total travel time and fuel burn are 433 minutes and 56,800 $\mathrm{kg}$ respectively along the TFMS track. The flight track-based trajectory flies at lower latitudes and avoids crossing two Canadian Centers near the origin airport and it flies over two Canadian Centers for a total of $1,228 \mathrm{~km}$. It also traveled through GANDER and SHANWICK oceanic FIRs for 2,667 km and flew over EISN FIR for $579 \mathrm{~km}$. The total over-flight charges are $\$ 1400$.

The fuel-optimal trajectory saves potentially $3.0 \%$ or $1,700 \mathrm{~kg}$ of fuel burn when compared to that of trajectory based on TFMS track. Assuming the price of jet fuel is $\$ 2.8$ per gallon, i.e., $\$ 0.91$ per kilogram, the total fuel cost is $\$ 50,200$ for the fuel-optimal trajectory and $\$ 51,700$ for the track-based trajectory. The fuel-optimal trajectory could potentially save $\$ 1500$ in fuel charges but costs $\$ 400$ more in the over-flight charges. Based on AEDT, a total of $5,355 \mathrm{~kg}$ of $\mathrm{CO}_{2}$ emissions can be potentially reduced when flying along the fuel-optimal trajectory. 


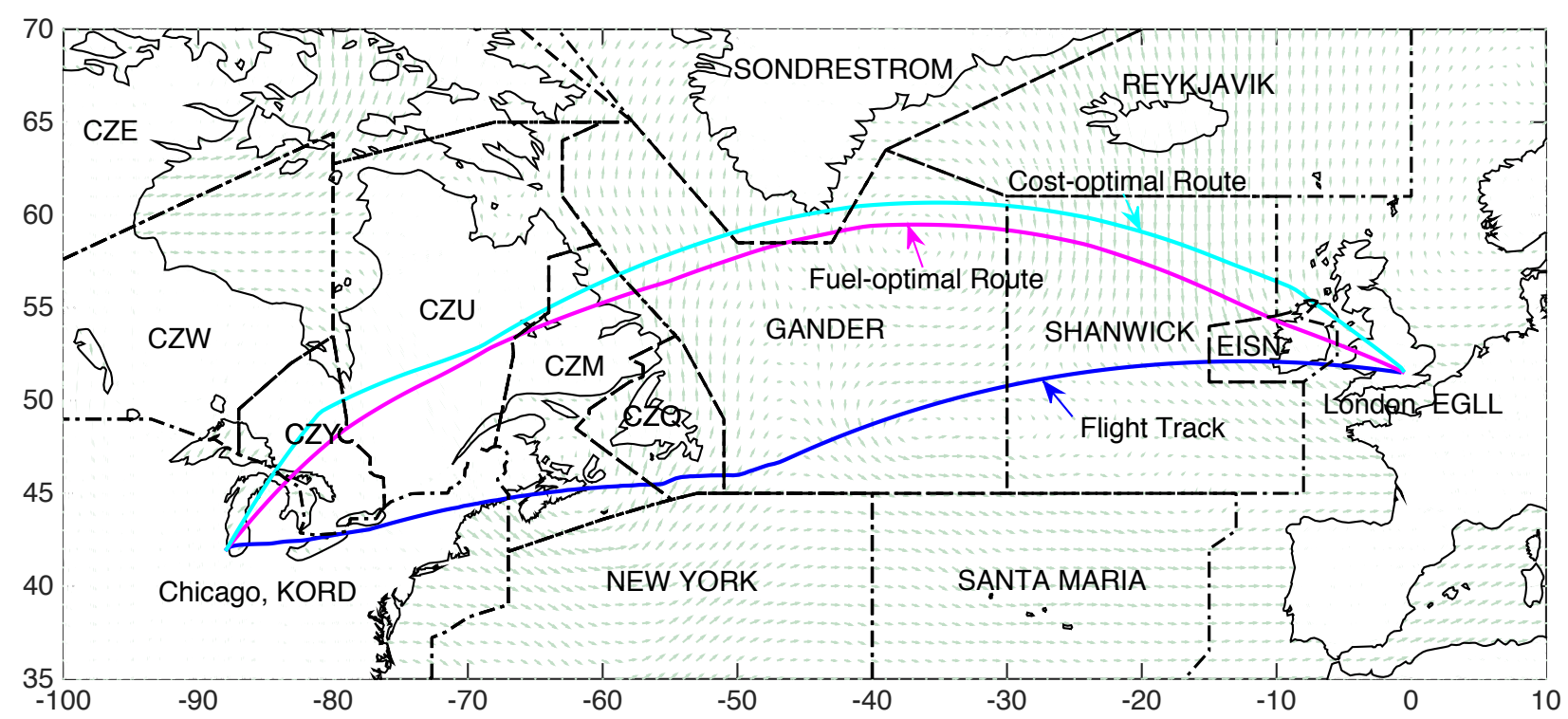

Figure 2. Horizontal trajectories for a transatlantic flight from Chicago to London at 35,000 feet. Fueloptimal trajectory is the magenta and actual flight track is blue.

In this example, the fuel saving due to flying fuel-optimal trajectory is larger than the additional over-flight charges. Flying the fuel-optimal trajectory reduced the operational cost and the environmental impact due to aircraft emissions. In general, the potential fuel savings may be smaller for other flights subject to en route wind conditions and the departure times. The fuel cost savings can be overtaken by the additional over-flight charges if the expected fuel saving is less than $500 \mathrm{~kg}$. Therefore, the over-flight charges can cause a flight to deviate from its fuel optimal path, which produces minimum aircraft emissions, for minimizing the actual operational cost.

The cost-optimal trajectory is computed based on the cost function defined by Eq. (3) in Section III. It is located to the North of the fuel-optimal trajectory. The travel time is 422 minutes and the fuel burn is $55,600 \mathrm{~kg}$. Similar to that of the fuel-optimal route, the cost-optimal trajectory flies over three Canadian Centers for a total of 2,136 km and traveled through GANDER, SONDRESTROM, and SHANWICK oceanic FIRs; but it avoids crossing Shannon (EISN) FIR. The total fuel cost is $\$ 50,600$ and the over-flight charges are $\$ 1,400$. The cost-optimal trajectory incurs higher fuel consumption and aircraft emissions but incurs lower airspace charges en route and approximately the same total operational cost of $\$ 52,000$ when compared to the fuel-optimal trajectory. It has lower fuel cost and almost the same over-flight charges when compared to the flight track-based trajectory. Table 3 summarizes the performance of the three trajectories.

Table 3. Trajectory performances for the transatlantic flight from Chicago to London.

\begin{tabular}{|c|c|c|c|c|c|c|}
\hline $\begin{array}{c}\text { Trajectory } \\
\text { Type }\end{array}$ & $\begin{array}{c}\text { Travel Time } \\
(\text { minutes })\end{array}$ & $\begin{array}{c}\text { Fuel Burn } \\
(\mathrm{kg})\end{array}$ & $\begin{array}{c}\text { Airspace Distance } \\
(\mathrm{km})\end{array}$ & $\begin{array}{c}\text { Airspace } \\
\text { Charges }(\$)\end{array}$ & $\begin{array}{c}\text { Fuel Cost } \\
(\$)\end{array}$ & $\begin{array}{c}\text { Total Cost } \\
(\$)\end{array}$ \\
\hline Flight Track & 433 & 56,800 & 4,474 & 1,400 & 51,700 & 53,100 \\
\hline Fuel-optimal & 418 & 55,100 & 5,383 & 1,800 & 50,200 & 52,000 \\
\hline Cost-optimal & 422 & 55,600 & 5,040 & 1,400 & 50,600 & 52,000 \\
\hline
\end{tabular}

\section{B. Fuel Cost and Airspace Charges for Transatlantic Flights}

The flight simulation is extended for all transatlantic flights during July 2012 based on the fuel-optimal routes, cost-optimal routes and the actual flight tracks. The number of flights in the simulation varied between 706 and 855 and the total number of flights in the simulation is 24,994 . The fuel cost and over-flight charges are assessed for the three types of trajectories over the entire month. Figure 3a plots the aggregated fuel cost for the entire fleet each day during July 2012. Figure $3 \mathrm{~b}$ plots the total over-flight charges similarly. The results for fuel-optimal routes, costoptimal routes and actual flight tracks are presented in magenta, black, and blue, respectively. The fuel-optimal routes consume the lowest fuel burn for all days over the entire period. The fuel costs are calculated based on aircraft type per flight and by assuming that the price of jet fuel is $\$ 2.8$ per gallon i.e. $\$ 0.91$ per kilogram. The daily fuel cost depends on the number of flights operated that day with estimated mean fuel costs of $\$ 37.58$ million, $\$ 37.76$ million and $\$ 38.36$ million respectively. The over-flight charges are computed based on the heavy takeoff 
weight typical for an aircraft type and the airspace model described in Section III.B along three different routes for each flight. The daily mean over-flight charges are \$2.09 million, \$1.68 million and \$2.04 million respectively. The over-flight charges are about $6 \%$ of the fuel cost on average. The cost-optimal routes have the lowest over-flight charges and slightly higher fuel costs than those of the fuel-optimal routes for each day during July 2012. The fueloptimal routes have the highest over-flight charges since they are not considered in the objective cost function. The actual flight tracks have the highest fuel cost and total operating cost due to a more complex objective cost function considered during flight planning and additional route and airspace constraints encountered during real-time operations.

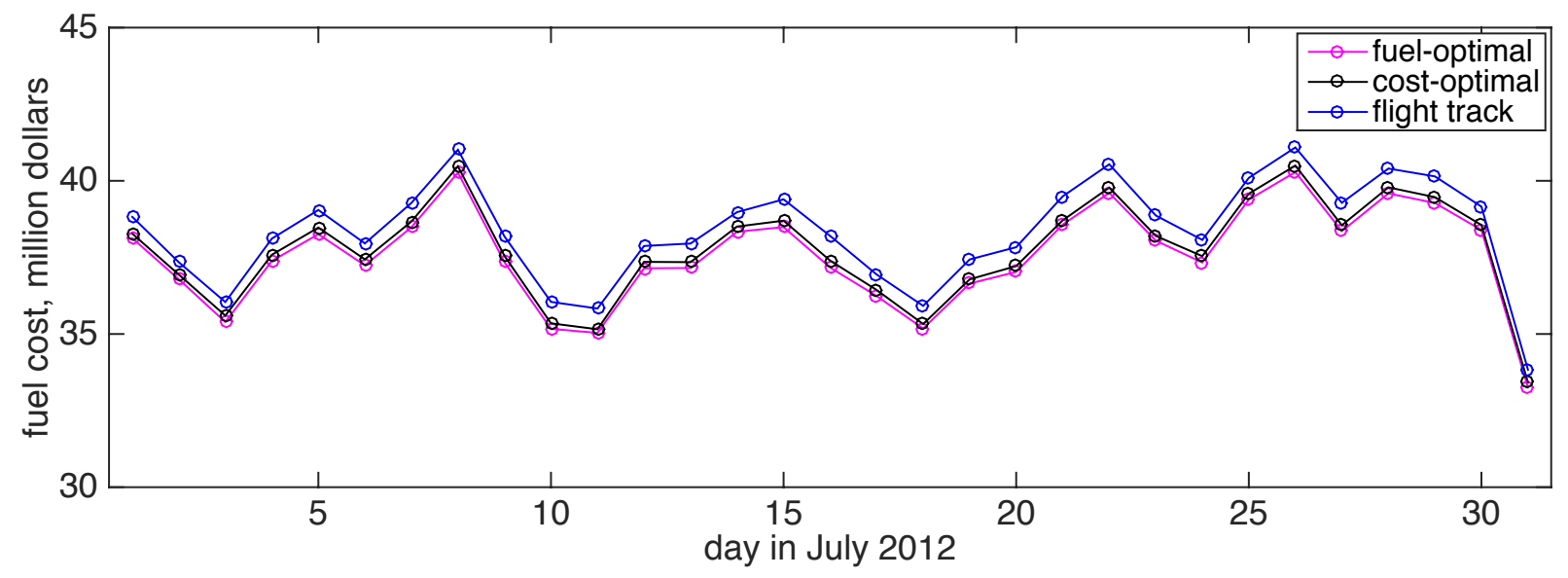

Figure 3a. Total Fuel cost for the transatlantic flights during July, 2012 resulting from flying the fuel-optimal routes (magenta), cost-optimal routes (black), and actual flight tracks (blue).

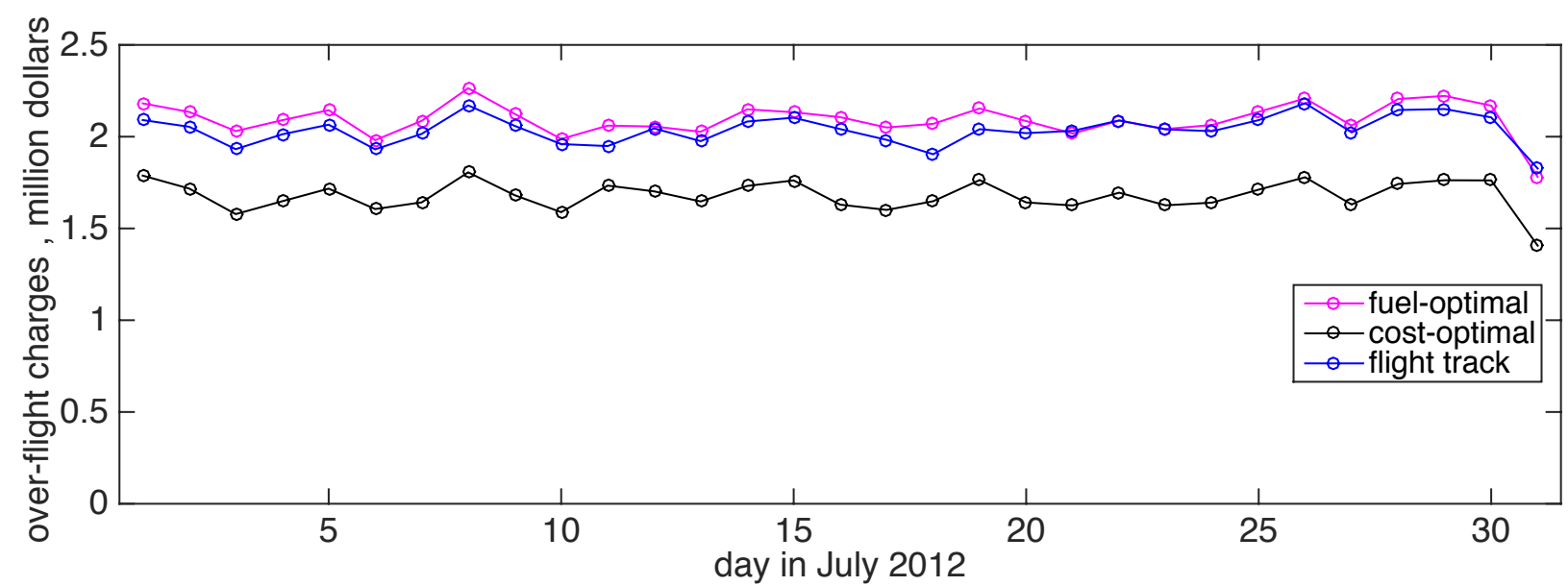

Figure 3b. Total over-flight charges for the transatlantic flights during July, 2012 resulting from flying the fuel-optimal routes (magenta), cost-optimal routes (black), and actual flight tracks (blue).

Figure 4 plots the potential savings for fuel-optimal trajectories in blue and for cost-optimal trajectories in magenta for each day during July 2012. The potential savings are measured in terms of percent reduction compared to flight-track based trajectories for over-flight charges, fuel cost, and the total cost respectively. The mean overflight charges daily for the entire month is $2.8 \%$ higher with $2.1 \%$ standard deviation for the fuel-optimal trajectories and $17.6 \%$ lower with $2.3 \%$ standard deviation for the cost-optimal trajectories. The mean savings of fuel cost is $2.0 \%$ for the fuel-optimal trajectories and $1.6 \%$ for the cost-optimal trajectories. The mean savings of total operating cost is $1.8 \%$ for the fuel-optimal trajectories and $2.4 \%$ for the cost-optimal trajectories. The mean savings for fuel and total cost have a narrow range with around $0.3 \%$ standard deviation.

The average daily operating costs for the fleet during July 2012 are listed in Table 4. Based on the comparison of the flight track trajectories and the cost-optimal trajectories for the transatlantic air traffic during July 2012, the 
transatlantic flights can potentially save $\$ 600,000$ in fuel cost plus $\$ 360,000$ in airspace charges daily from flying the cost-optimal routes. In addition, the aircraft emissions can be potentially reduced by 2,070 metric tons each day.

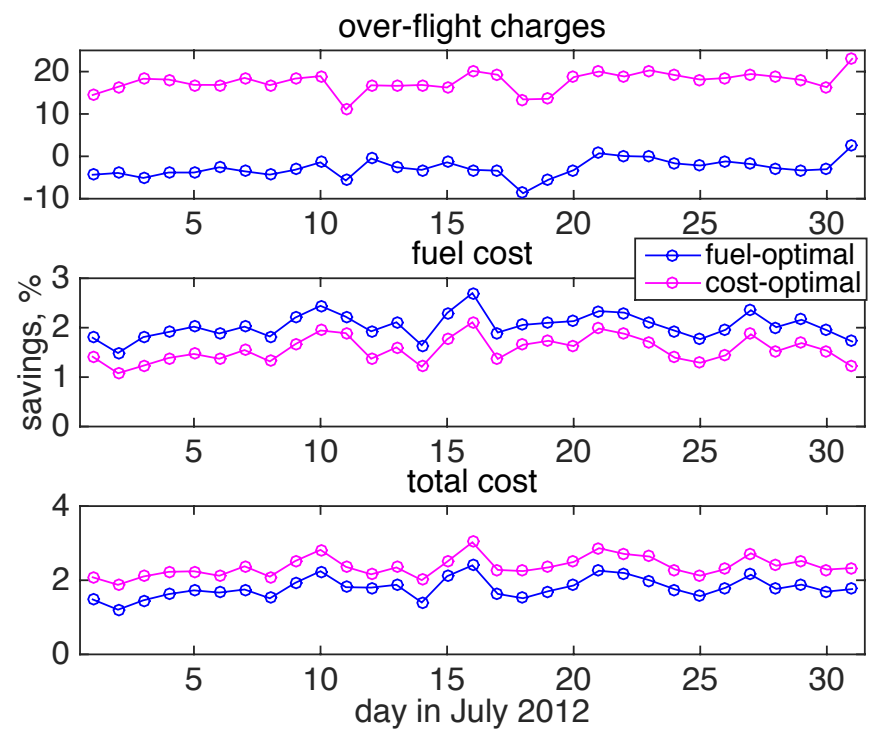

Figure 4. Potential savings for over-flight charges, fuel cost, and total operating cost when the fuel-optimal routes (blue) and cost-optimal routes (magenta) are compared with the actual flight tracks during July 2012.

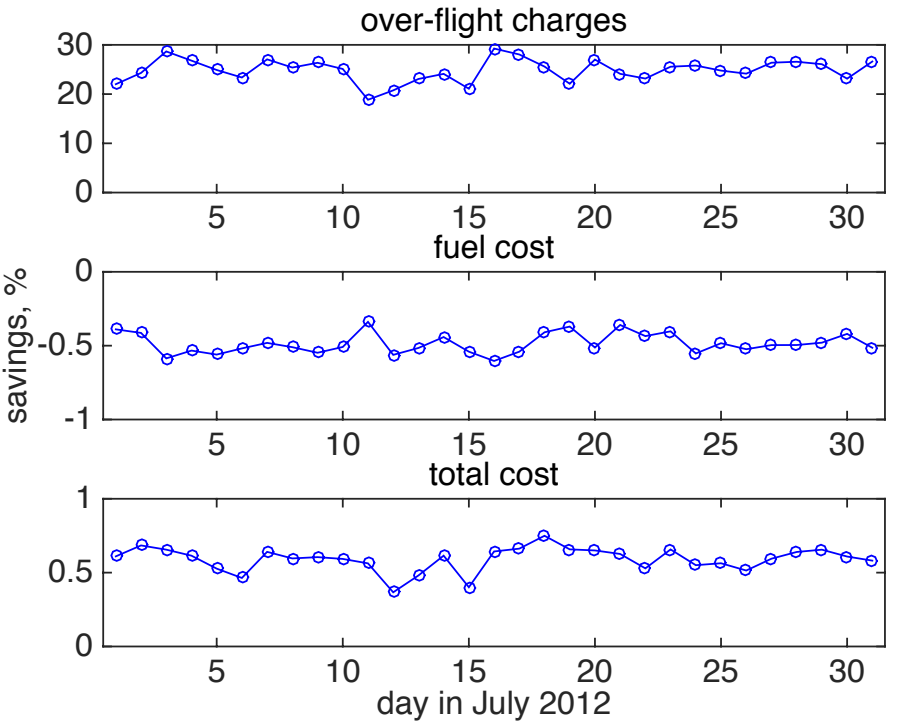

Figure 5. The differences in airspace charges, fuel cost, and total operating cost when the cost-optimal routes are compared to the fuel-optimal routes during July 2012.

Table 4. Daily mean operating costs for the fleet during July, 2012.

\begin{tabular}{|c|c|c|c|}
\hline Trajectory Type & $\begin{array}{c}\text { Airspace Charges } \\
\text { (\$ millions) }\end{array}$ & $\begin{array}{c}\text { Fuel Cost } \\
\text { (\$ millions) }\end{array}$ & $\begin{array}{c}\text { Total Cost } \\
\text { (\$ millions) }\end{array}$ \\
\hline Flight Track & 2.04 & 38.36 & 40.40 \\
\hline Fuel-optimal & 2.09 & 37.58 & 39.67 \\
\hline Cost-optimal & 1.68 & 37.76 & 39.44 \\
\hline
\end{tabular}


These results suggest that the cost-optimal trajectories that include both airspace charges and fuel cost in the objective function during the optimization have larger savings in airspace charges and in total cost. In addition, the potential savings by comparing the fuel-optimal trajectories to the cost-optimal trajectories for each day over the period are plotted in Fig. 5. The cost-optimal trajectories can potentially save $24.8 \%$, i.e. $\$ 410,000$ of airspace charges daily but require around $0.5 \%$ additional fuel, i.e. $\$ 180,000$ additional fuel cost, when compared to the fueloptimal trajectories over the month. Based on the comparison of the fuel-optimal trajectories and the cost-optimal trajectories for the transatlantic air traffic during July 2012, the potential daily savings for the total operating cost for the entire fleet is about $0.6 \%$, i.e. $\$ 230,000$. The percent savings for the entire fleet varies slightly depending on the air traffic and weather conditions over the period. Note that the potential cost of fuel burn and airspace charges saved from the cost-optimal routes depend on the aircraft types, airport pairs and the direction of transatlantic air traffic. The past study ${ }^{6}$ presented analytical results based on the fuel-optimal trajectories. The aggregated results presented in this section can be further interrogated to obtain detailed analytical results similar to those presented in the previous study ${ }^{6}$ based on the cost-optimal trajectories.

\section{Impact of airspace charges on fuel and $\mathrm{CO}_{2}$ emissions}

The potential impact of airspace charges for the transatlantic flights is evaluated based on the additional fuel consumption and aircraft emissions resulting from flying the cost-optimal trajectories. Section V.A ranks the top 10 airport pairs by additional fuel burn due to airspace charges and ranks the top 10 airspace regions by traversed distance and collected airspace charges along the optimal trajectories. Section V.B generates and analyzes the costoptimal trajectories by varying the jet fuel price.

\section{A. Potential Impact of Airspace Charges}

The additional fuel burn is computed by direct comparison of the cost-optimal trajectory and the fuel-optimal trajectory for each transatlantic flight. The mean and aggregated additional fuel burn associated with each airport pair is computed and sorted for eastbound and westbound transatlantic air traffic for the month of July 2012. The top 10 airport pairs that have the highest total additional fuel burn are listed in descending order in Table 5 for the eastbound and westbound traffic, respectively. Westbound airport pairs have a relatively lower additional fuel burn over the period. These results are consistent to those found in the previous study ${ }^{6}$ that fewer westbound flights deviated far away from the fuel-optimal routes due to the presence of stronger head winds. In general, westbound transatlantic flights operate in the presence of strong head winds that are penalized with higher fuel burn and fuel cost for not flying fuel-optimal routes. The range of total additional fuel burn for the eastbound traffic during July 2012 is between 266 metric tons and 50 metric tons, while it is between 185 metric tons and 45 metric tons for westbound traffic. Note that many of these airport pairs are also the busiest since the aggregated result also depends on the number of flight operations.

Table 5. Top ten airport pairs ranked by total additional fuel burn in metric tons during July 2012.

\begin{tabular}{|c|c|c|c|c|}
\hline Rank & Eastbound Airport Pairs & Total (metric tons) & Westbound Airport Pairs & Total (metric tons) \\
\hline 1 & KJFK-LFPG & 266 & LFPG-KJFK & 185 \\
\hline 2 & KJFK-EGLL & 187 & LLBG-KJFK & 90 \\
\hline 3 & KEWR-EGLL & 86 & EDDF-KORD & 88 \\
\hline 4 & KIAH-LFPG & 76 & LLBG-KEWR & 75 \\
\hline 5 & KBOS-LFPG & 76 & LTBA-KJFK & 72 \\
\hline 6 & KORD-EGLL & 70 & LFPG-KBOS & 58 \\
\hline 7 & KJFK-LTBA & 62 & LFPG-KLAX & 57 \\
\hline 8 & KATL-LFPG & 56 & LFPG-KORD & 49 \\
\hline 9 & KEWR-LLBG & 51 & LFPG-KATL & 48 \\
\hline 10 & KDFW-EGLL & 50 & EDDF-KLAX & 45 \\
\hline
\end{tabular}

The top 10 airport pairs that have the highest mean additional fuel burn among the 100 busiest airport pairs for the transatlantic flights are listed in descending order in Table 6 for the eastbound and westbound traffic respectively. Similarly, westbound airport pairs have a relatively lower additional fuel burn on average over the period. The eastbound flights arriving at Paris Charles De Gaulle (LFPG), Istanbul Ataturk (LTBA), Israel Ben Gurion (LLBG), London Gatwick (EGKK), Zurich (LSZH), and Rome Fiumicino (LIRF) and the westbound flights departed from LLBG, Frankfurt (EDDF), LFPG, and LTBA have the highest mean additional fuel burn. The range of total additional fuel burn per eastbound flight is between 1 metric tons and 0.4 metric tons while each westbound 
flight is between 0.9 metric tons and 0.5 metric tons. These airports are located close to the airspaces that have high en-route charges as shown in Fig. 1. These results provide an insight to the impact of airspace charges on flight path planning. The transatlantic flights operating between the high-ranked airport pairs are more likely to deviate from their fuel-optimal path. They have a higher potential for fuel savings resulting from flying fuel-optimal routes when their airspace charges are discounted. In addition, aircraft types operating in the fleet can also be chosen to gain maximum savings of fuel and aircraft emissions.

Table 6. Top ten airport pairs ranked by mean additional fuel burn in metric tons during July 2012.

\begin{tabular}{|c|c|c|c|c|}
\hline Rank & Eastbound Airport Pairs & Mean (metric tons) & Westbound Airport Pairs & Mean (metric tons) \\
\hline 1 & KIAH-LFPG & 1.0 & LLBG-KJFK & 0.9 \\
\hline 2 & KJFK-LFPG & 0.9 & LLBG-KEWR & 0.8 \\
\hline 3 & KBOS-LFPG & 0.9 & EDDF-KLAX & 0.7 \\
\hline 4 & KJFK-LTBA & 0.7 & LFPG-KLAX & 0.7 \\
\hline 5 & KEWR-LLBG & 0.6 & LFPG-KBOS & 0.6 \\
\hline 6 & KSFO-LFPG & 0.6 & LFPG-KSFO & 0.6 \\
\hline 7 & KMCO-EGKK & 0.5 & LFPG-KJFK & 0.6 \\
\hline 8 & KJFK-LLBG & 0.5 & LTBA-KJFK & 0.6 \\
\hline 9 & KJFK-LSZH & 0.5 & LFPG-KATL & 0.5 \\
\hline 10 & KJFK-LIRF & 0.4 & LFPG-KPHL & 0.5 \\
\hline
\end{tabular}

The potential changes of air traffic patterns for transatlantic flights are investigated based on the fuel-optimal trajectories and the cost-optimal trajectories. The regions of airspace traversed by transatlantic flights during July 2012 are ranked according to the total travel distance and the airspace charges for the fuel-optimal and cost-optimal trajectories respectively. Table 7 lists the top 10 airspace regions that have the longest travel distance in descending order resulting from the fuel-optimal trajectories and cost-optimal trajectories respectively. The top ranked airspace regions traversed by the two types of trajectories are almost exactly the same except that the fuel-optimal trajectories travel through Shannon (EISN) FIR and Scottish (EGPX) FIR but the cost-optimal trajectories seem to avoid these FIRs. This is partly evident by the sample flight shown in Section IV.A and due to relatively high airspace charges.

Table 7. Top ten airspace regions ranked by total travel distance flown by the fuel-optimal routes and flown by the cost-optimal routes during July 2012.

\begin{tabular}{|c|c|c|c|c|}
\hline Rank & Fuel-optimal Routes & $\begin{array}{c}\text { Travel Distance } \\
(\text { million km })\end{array}$ & Cost-optimal Routes & $\begin{array}{c}\text { Travel Distance } \\
(\text { million km })\end{array}$ \\
\hline 1 & GANDER, Canada & 33 & GANDER, Canada & 34 \\
\hline 2 & SHANWICK, Ireland & 17 & SHANWICK, Ireland & 19 \\
\hline 3 & CZMH, Canada & 14 & CZMH, Canada & 12 \\
\hline 4 & CZUH, Canada & 9 & CZUH, Canada & 7 \\
\hline 5 & CZQH, Canada & 6 & CZQH, Canada & 5 \\
\hline 6 & SONDRESTROM, Greenland & 5 & REYKJAVIK, Iceland & 4 \\
\hline 7 & EISN, Ireland & 5 & SONDRESTROM, Greenland & 4 \\
\hline 8 & EGTT, England & 5 & EGTT, England & 4 \\
\hline 9 & REYKJAVIK, Iceland & 5 & CZWH, Canada & 4 \\
\hline 10 & EGPX, Scotland & 4 & EISN, Ireland & 3 \\
\hline
\end{tabular}

Table 8 lists the top 10 airspace regions that have the highest airspace charges collected in descending order resulting from the fuel-optimal trajectories and cost-optimal trajectories, respectively. The ten airspace regions that collect the highest airspace charges are almost the same for the fuel-optimal trajectories and the cost-optimal trajectories although their rankings are different. Flying fuel-optimal routes potentially increases the total airspace charges collected by the top three airspace regions by $43 \%$ from $\$ 21$ million to $\$ 30$ million over the period when compared to that of the cost-optimal trajectories. These airspace regions account for $60 \%$ and $53 \%$ of total airspace charges among the top airspaces. Due to the potential increase of the total airspace charges resulting from flying fuel-optimal routes, there may be room for offering discounts on the en route charges by the top three airspaces to promote fuel-optimal flights for reducing aircraft emissions without the decrease in total collected airspace charges. 
Table 8. Top ten airspace regions ranked by total airspace charges for the fuel-optimal routes and for the cost-optimal routes during July 2012.

\begin{tabular}{|c|c|c|c|c|}
\hline Rank & Fuel-optimal Routes & $\begin{array}{c}\text { Airspace Charges } \\
\text { (million dollars) }\end{array}$ & $\begin{array}{c}\text { Cost-optimal } \\
\text { Routes }\end{array}$ & $\begin{array}{c}\text { Airspace Charges } \\
\text { (million dollars) }\end{array}$ \\
\hline 1 & EGTT, England & 12 & EGTT, England & 10 \\
\hline 2 & EGPX, Scotland & 10 & CZMH, Canada & 7 \\
\hline 3 & CZMH, Canada & 8 & EGPX, Scotland & 4 \\
\hline 4 & CZUH, Canada & 5 & CZUH, Canada & 4 \\
\hline 5 & EISN, Ireland & 4 & CZQH, Canada & 3 \\
\hline 6 & CZQH, Canada & 3 & EISN, Ireland & 3 \\
\hline 7 & CZWH, Canada & 2 & LFRR, France & 3 \\
\hline 8 & GANDER, Canada & 2 & CZWH, Canada & 2 \\
\hline 9 & EHAA, Netherlands & 2 & GANDER, Canada & 2 \\
\hline 10 & LFRR, France & 2 & LFFF, France & 2 \\
\hline
\end{tabular}

The potential changes of air traffic patterns due to airspace charges for transatlantic flights can be identified by direct comparison of the aircraft distance flown inside each Center and FIR flying the fuel-optimal routes and the cost-optimal routes. The ten airspace regions outlined by blue dashed-line in Fig. 6 have the largest difference when the travel distance of fuel-optimal trajectories is subtracted by that of cost-optimal trajectories. They are ranked and denoted in blue text in Fig. 6 and Table 9. Similarly, the ten FIRs that have the largest difference when the travel distance of cost-optimal trajectories is subtracted by that of fuel-optimal trajectories are outlined by magenta line in Fig. 6. Their rankings are denoted in magenta text in Fig. 6 and Table 9. Fuel-optimal trajectories tend to traverse the Canadian-controlled centers in North America, the SONDRESTROM and REYKJAVIK FIRs over the North Atlantic Ocean and U.K.-controlled Centers in Europe. Cost-optimal trajectories tend to avoid Centers over U.K. by splitting into two traffic flows. One flow goes to North and the majority to south and cross GANDER and SHANWIC FIRs over the ocean. Table 9 lists the FIRs associated to the ranks denoted in Fig. 6 and the difference of travel distance between the two types of trajectories. These results suggest that the Canadian FIRs and the Scottish, Irish, and British FIRs have good potential to provide discounts to en-route transatlantic air traffic for fuel conservation and aircraft emission reductions. Congestion can occur at these airspace regions due to the increase of air traffic resulting from lower airspace charges. The approach in the recent study ${ }^{8}$ can be applied to adjust departure times for the affected transatlantic flights for minimization of potential aircraft conflicts and airspace congestion.

Table 9. The top 10 airspace regions denoted in Figure 6 and the associated difference of traversed distance between the fuel-optimal routes and the cost-optimal routes during July 2012.

\begin{tabular}{|c|c|c|c|c|c|}
\hline Rank & $\begin{array}{c}\text { Fuel-optimal } \\
\text { Routes Preferred }\end{array}$ & $\begin{array}{c}\text { Distance } \\
\text { Difference } \\
\text { (million km) }\end{array}$ & Rank & $\begin{array}{c}\text { Cost-optimal } \\
\text { Routes Preferred }\end{array}$ & $\begin{array}{c}\text { Distance } \\
\text { Difference } \\
(\mathrm{million} \mathrm{km})\end{array}$ \\
\hline 1 & EGPX, Scotland & 2.6 & 1 & SHANWICK, Ireland & 2.5 \\
\hline 2 & CZUH, Canada & 2.5 & 2 & GANDER, Canada & 0.7 \\
\hline 3 & CZMH, Canada & 1.9 & 3 & LFRR, France & 0.6 \\
\hline 4 & EISN, Ireland & 1.5 & 4 & ENOR, Norway & 0.4 \\
\hline 5 & SONDRETROM, Greenland & 1.2 & 5 & LFFF, France & 0.2 \\
\hline 6 & CZQH, Canada & 1.0 & 6 & LDZO, Croatia & 0.07 \\
\hline 7 & EGTT, England & 0.9 & 7 & LIMM, Italy & 0.05 \\
\hline 8 & REYKJAVIK, Iceland & 0.6 & 8 & ESAA, Sweden & 0.05 \\
\hline 9 & CZEH, Canada & 0.5 & 9 & LFBB, France & 0.04 \\
\hline 10 & CZYH, Canada & 0.5 & 10 & LFEE, France & 0.03 \\
\hline
\end{tabular}



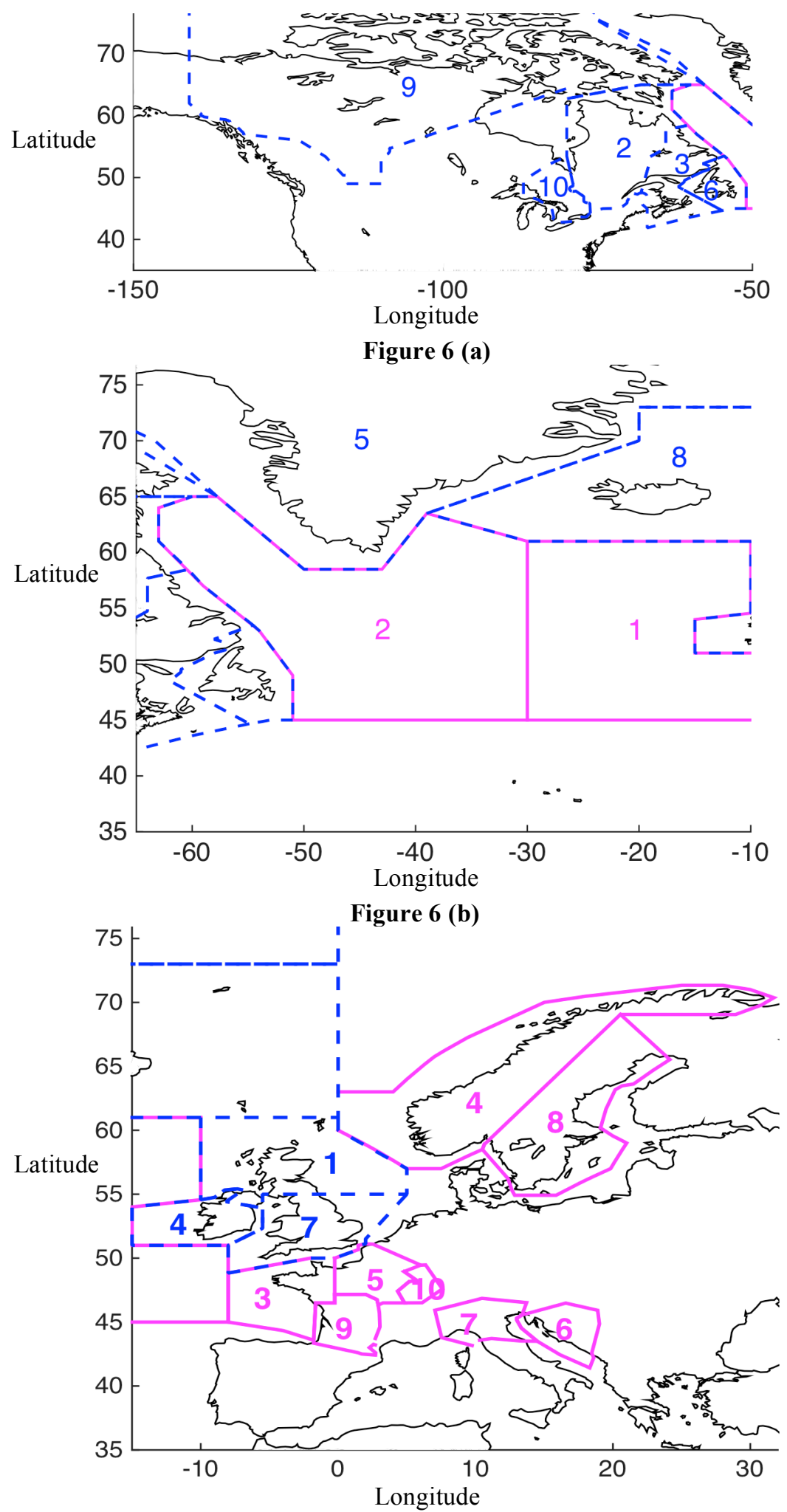

Figure 6 (c)

Figure 6. Top airspace regions in (a) North America, (b) North Atlantic Ocean, and (c) Europe ranked by difference of total travel distance between the fuel-optimal routes and the cost-optimal routes during July 2012. 


\section{B. Impact of Fuel Price}

This section generates and analyzes the cost-optimal trajectories by varying the jet fuel price. The analysis performed in the previous subsections varies with the jet fuel price. The price index ${ }^{15}$ of jet fuel is defined as 100 when the jet fuel price was $\$ 0.87 / \mathrm{gal}$ and approximately $\$ 0.28 / \mathrm{kg}$ during the year 2000 . The price index for jet fuel varied from 350 to 170 between March 2014 and March 2015 as the price of jet fuel varied from $\$ 0.98 / \mathrm{kg}$ to about $\$ 0.50 / \mathrm{kg}$ during this period. The impact of airspace charges on flight routing increases as fuel cost decreases. On the contrary, the cost-optimal trajectories are closer to those of the fuel-optimal trajectories as the fuel cost increases.

Based on the historical jet fuel price, the cost-optimal trajectories are generated for all transatlantic flights during July 15,2012 with price variation of jet fuel from $\$ 0.30 / \mathrm{kg}$ to $\$ 1.30 / \mathrm{kg}$. Eleven sets of cost-optimal trajectories are generated; and each set assumes a different fuel price within the range with $\$ 0.10 / \mathrm{kg}$ increments. The total aircraft fuel burn is assessed for each trajectory set and compared to those of fuel-optimal trajectories on July 15, 2012. The bar chart in Fig. 7 plots the additional fuel burn of the cost-optimal trajectories for various fuel prices when compared to the fuel-optimal trajectories on July 15, 2012. The additional fuel burn is the largest for the lowest fuel price as aircraft can fly a longer route to avoid crossing FIRs with relatively high airspace charges when jet fuel is more affordable. The additional fuel burn decreases from 1,040 metric tons to 130 metric tons non-uniformly when fuel price increases from $\$ 0.30 / \mathrm{kg}$ to $\$ 1.30 / \mathrm{kg}$. The percent reduction of additional fuel drops from $24 \%$ to $22 \%$ for each 10 cents decrease in fuel price between $\$ 0.30 / \mathrm{kg}$ and $\$ 0.80 / \mathrm{kg}$. Then, it drops from $22 \%$ to $13 \%$ for each 10 cents decrease for fuel price ranging between $\$ 0.80 / \mathrm{kg}$ and $\$ 1.30 / \mathrm{kg}$. The results presented in the previous subsections assume a fuel price of $\$ 0.91 / \mathrm{kg}$; and that has a corresponding additional fuel burn of 264 metric tons. It will increase by $239 \%$ to 630 metric tons as fuel prices dropped to about $\$ 0.50 / \mathrm{kg}$ in March 2015 .

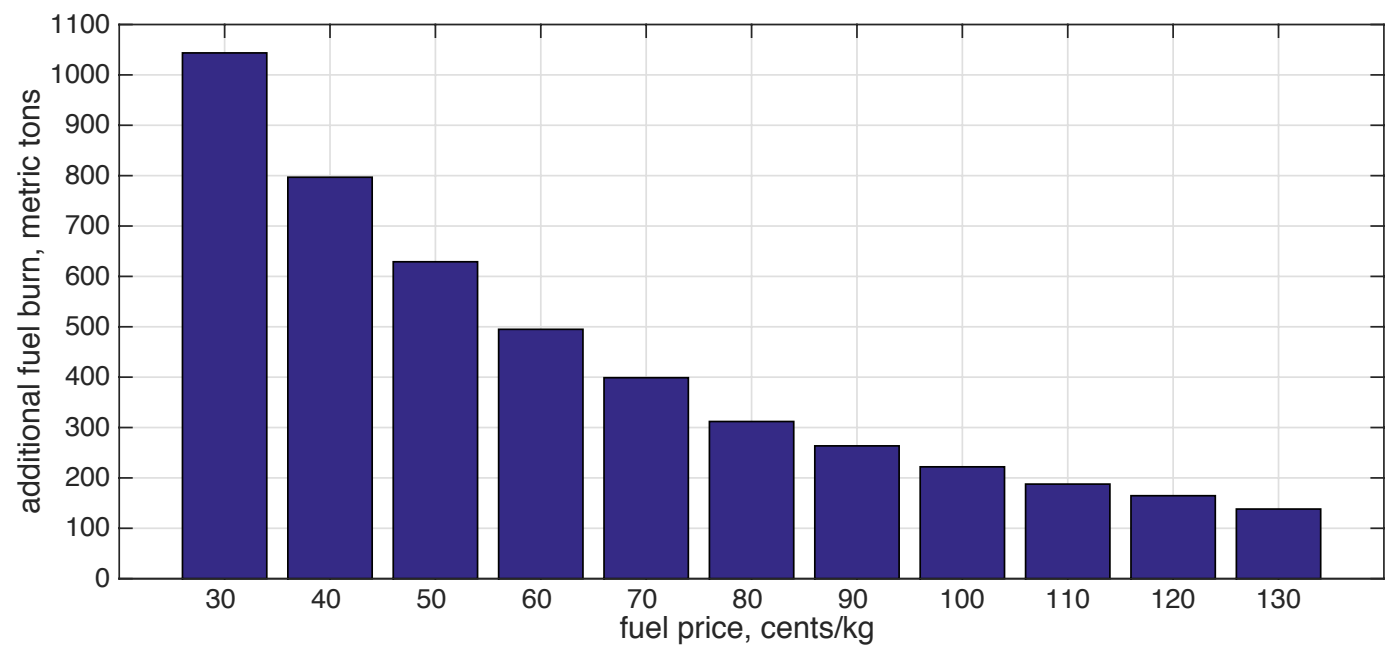

Figure 7. Variation of additional fuel consumption with jet fuel price for the cost-optimal trajectories during July 2012.

\section{Conclusion}

This study develops an algorithm to calculate wind-optimal trajectories for aircraft while minimizing airspace charges en route. The operational strategies investigated in this study for minimizing aircraft fuel burn and emissions include flying fuel-optimal routes and flying cost-optimal routes that minimize airspace charges en-route. The results in this paper use traffic data for transatlantic flights during July 2012. The mean daily savings in airspace charges, fuel cost and total operating cost during the period are $17.6 \%, 1.6 \%$, and $2.4 \%$ respectively, along the costoptimal trajectories. The transatlantic flights can potentially save $\$ 600,000$ in fuel cost plus $\$ 360,000$ in over-flight charges daily from flying the cost-optimal trajectories. In addition, the aircraft emissions can be potentially reduced by 2,070 metric tons each day. The airport pairs and airspace regions that have the highest potential impacts due to airspace charges are identified for possible reduction of fuel burn and aircraft emissions for the transatlantic flights. Due to the potential increase of the total airspace charges resulting from flying fuel-optimal routes, there may be room for offering discounts on the en route charges by the top three airspace regions to promote fuel-optimal flights for reducing aircraft emissions without the decrease in total collected airspace charges. The results in the paper show 
that the impact of the variation in fuel price on the optimal routes is to reduce the difference between wind-optimal and cost-optimal routes as the fuel price increases. The additional fuel consumption is quantified using the large variation in the fuel prices during March 2014 to March 2015.

\section{References}

${ }^{1}$ Roberson, B., "Fuel Conservation Strategies: Cost Index Explained," Aero Quarterly, 2" ${ }^{\text {nd }}$ Quarter, 2007.

${ }^{2}$ Roberson, W., Root, R., and Adams, D., "Fuel Conservation Strategies: Cruise Flight," Aero Quarterly, $4{ }^{\text {th }}$ Quarter, 2007.

${ }^{3}$ Reynolds, T.G., "Analysis of Lateral Flight Inefficiency in Global Air Traffic Management," 8th AIAA Aviation Technology, Integration and Operations Conference, Anchorage, Alaska, 14-19 September 2008.

${ }^{4}$ Howell, D., Bennett, M., Bonn, J. and Knorr, D., "Estimating the En Route Efficiency Benefits Pool”, 5th USA/Europe Air Traffic Management Seminar, Budapest, 2003.

${ }^{5}$ Kettunen, T., Hustache, J.C., Fuller, I., Howell, D., Bonn, J. and Knorr, D., "Flight Efficiency Studies in Europe and the United States", 6th USA/Europe Air Traffic Management Seminar, Baltimore, 2005.

${ }^{6}$ Sridhar, B., Ng, H. K., Linke, F., and Chen, N. Y., "Benefits Analysis of Wind-Optimal Operations for Trans-Atlantic Flights," AIAA Aviation Technology, Integration, and Operation Conference, June 2014, Atlanta, GA.

${ }^{7}$ Post, J., Bonn, J., and Shresta, S., "NAS-Wide simulation applied to reduced oceanic separation scenarios,"Integrated Communications, Navigation and Surveillance Conference (ICNS), Herndon, VA, April 2013.

${ }^{8}$ Rodionova, O., Sbihi, M., Delahaye, D., and Mongeau, M., "Optimization of aircraft trajectories in North Atlantic oceanic airspace." 5th International Conference on Research in Air Transportation, University of California, Berkeley, CA, May 2012.

${ }^{9}$ Bryson, A. E., and Ho, Y. C., Applied Optimal Control, Taylor and Francis, Levittown, PA, 1975.

${ }^{10}$ "Customer Guide to Charges," NAV CANADA

11“Adjusted unit rates applicable to September 2014 flights," Eurocontrol Central Route Charges Office.

${ }^{12} \mathrm{Ng}$, H. K., Sridhar, B., Grabbe, S., and Chen, N., "Cross-Polar Aircraft Trajectory Optimization and the Potential Climate Impact," IEEE/AIAA 30 $0^{\text {th }}$ Digital Avionics Systems Conference, Oct. 2011.

13“"User Manual for the Base of Aircraft Data (BADA), Revision 3.6," Eurocontrol Experimental Center (EEC) Note No. 10/04, Project ACE-C-E2, Sept. 2004.

${ }^{14}$ Federal Aviation Administration, Washington, DC, Aviation Environmental Design Tool (AEDT) User Guide: Beta1c, October 2010.

${ }^{15}$ http://www.iata.org/publications/economics/fuel-monitor/Pages/price-development.aspx 